\section{Characteristics of Grapevine (Vitis vinifera L.) 'Albariño' Clones Resulting from Two Clonal Selections}

\author{
Susana Boso Alonso ${ }^{1}$, Virginia Alonso-Villaverde Pilar Gago, \\ José L. Santiago, and Mariá C. Martínez \\ Misión Biológica de Galicia (CSIC), Apartado de Correos 28, 36080 \\ Pontevedra, Spain
}

\author{
Emilio Rodriguez \\ Bodegas Terras Gauda S.A., Carretera Tui-A Guarda, As Eiras-O Rosal, \\ 36760 Pontevedra, Spain
}

Additional index words. Vitis vinifera, northwest Spain, ampelographic, agronomic, variability

\begin{abstract}
The grapevine cultivar Albariño (Vitis vinifera L.) is one of the most economically important of northwestern Spain. It is also grown in northern Portugal. The present work examines the results obtained by two clonal selection processes involving this cultivar. The first of these was begun in 1987 by the Viticulture Research Group of the Spanish Research Council (CSIC). This involved centuries-old mother plants showing small ampelographic or agronomic differences. The second process was begun in 1989 by the wine-making company Bodegas Terras Gauda S.A. This involved the use of centuriesold 'Albariño' plants too, but also of other plants no older than 20 years of age. The number of mother plants originally examined in the CISC procedure was 40, but only eight were finally selected and planted (at the Misión Biológica de Galicia Research Station). In the procedure followed by Bodegas Terras Gauda S.A., 115 mother plants were originally planted. The characteristics of the eight CSIC clones and the 22 surviving Bodegas Terras Gauda S.A. clones were determined. The variability of the eight CSIC clones was found to be greater. It is recommended that candidate materials for use in clonal selection programs be examined for differences in situ before being admitted to collections.
\end{abstract}

The grapevine cultivar Albariño (Vitis vinifera L.) has long been grown in northwestern Spain and the north of Portugal. The approval of the Appellation Contrôlée (A.C) "Rías Baixas" denomination in northwestern Spain in 1988 (Ministerio de Agricultura Pesca y Alimentación, 1988) led to an increasing demand for 'Albariño' grapes and to the substitution of low-quality cultivars and the hybrids they produced (then typical of post-Phylloxera Galicia) by 'Albariño'.

Because no clonal selection had ever been performed within this cultivar, the plants used in this restructuring were simply collected from old vineyards by growers. Therefore, the need for a selection program became evident. Around 1986, just a few years before the approval of the Rías Baixas A.C, a group of researchers from the Spanish Research Council (CSIC) anticipated this situation beginning the clonal selection of this cultivar together with other works carried out on grapevine varieties of northern and north-

Received for publication 19 July 2006. Accepted for publication 16 Sept. 2006.

This work was supported by the Ministerio de Ciencia y Tecnología, Spain, (HP2000-0032, RF02-004-C5-2), Bodegas Terras Gauda S.A., and the Xunta de Galicia (PGIDIT02TAL06E).

We thank Elena Zubiaurre and Iván González for technical assistance.

${ }^{1}$ To whom reprint requests should be addressed; e-mailsusanab@mbg.cesga.es. western Spain (Martínez and Mantilla, 1993, 1994). The selection criteria used required that the mother plants were 200 to 300 years old and also that they did not show external signs of viruses. Plants with these characteristics were sought all over Galicia, and 40 were eventually located. After several years of preliminary work (Martínez et al., 1994), eight of these plants that showed small ampelographic or agronomic differences were finally selected. Cuttings of each of these clones were planted at the Mision Biológica de Galicia (CSIC) research station plot and maintained under the same conditions for continued clonal selection. New ampelographic, agronomic (Boso et al., 2004a, 2005; Martínez et al., 2005), and molecular studies (Loureiro et al., 1998) were performed on these clones as well as on their natural resistance to downy mildew (Boso et al., 2004b, 2006).

Between 1989 and 1990, a group attached to the wine-making company Bodegas Terras Gauda S.A. also began to subject 'Albariño' to a clonal selection process. In this case, the selection procedure required the plants to have the shoots, leaves, and fruit clusters typical of the cultivar, if possible, to show differences in terms of the time at which they reached determined phenologic stages (flowering, fruit ripening, and so on) and that they show no external signs of viruses. In this program 115 mother plants were chosen from different vineyards in the Province of Ponte- vedra. The age of these plants was not taken into account, and material was collected from both centuries-old plants and others no more than 20 years old. All 115 were planted at the Bodegas Terras Gauda S.A. estate in 1992.

In 2002, Bodegas Terras Gauda S.A. contracted the CSIC viticulture research group to study their clones with the aim of defining their characteristics and determining which ones could produce the best wines taking into account the grown conditions at their plantations. The chance of cultivate grapes that allow their 'Albariño' wines to be distinguished from all others sharing this A.C. was desired by this winery. Because this request was similar to the CSIC's own program, this allowed the results achieved by these two selection procedures to be contrasted.

\section{Methods and Materials}

\section{Plant material}

This work was performed at two sites (both in the Province of Pontevedra, NW Spain, and both in the area where 'Albariño' is traditionally grown): one at the Misión Biológica de Galicia (MBG) Research Station (CSIC), $3 \mathrm{~km}$ from the city of Pontevedra, and the other at a property of Bodegas Terras Gauda S.A close to the border with Portugal (known as "El Rosal") (Fig. 1).

Eight clones were studied at the MBG plot: MBG-1, MBG-2, MBG-3, MBG-6; MBG-7, MBG-9, MBG-10, and MBG-11. All these clones come from centuries-old specimens (40 mother plants) found in Galicia between 1987 and 1989. Each centuriesold specimen was subjected to an in situ ampelographic study (Martínez and Mantilla, 1993; Martínez et al., 1994). Data on their agronomic characteristics were recorded before their introduction (data not published) to the MBG collection in 1993; only those that showed ampelographic or agronomic differences were admitted. All were grafted onto Richter 110 rootstocks and were randomly distributed in the same plot. Plants were grown en espalier with a distance between rows of $2.5 \mathrm{~m}$ and a distance between plants of $2 \mathrm{~m}$. All were pruned by the Sylvoz method, and all were subject to the same edaphoclimatic and cultivation conditions. The soil had a sandy loam texture. The phosphorus content of the soil was $132 \mathrm{ppm}$. The composition of the cation exchange complex was $[\mathrm{cmol}(+) / \mathrm{kg}]: 6.00$ in calcium, 0.53 in magnesium, and 0.55 in potassium. The organic matter content was $8.9 \%$. The soil was ploughed several times a year but received no irrigation. The mean annual temperature was $14.4{ }^{\circ} \mathrm{C}$; the mean annual rainfall was $1586 \mathrm{~mm}$ with strong annual variation. The characteristics of these eight clones (10 plants per clone) were studied over 5 consecutive years (2000-2004).

Twenty-two of the original 115 mother plants at the BTG site were studied (10 plants per clone). These received the designations B, C, D, E, F, H, I, J, K, L, M, N, Ñ, O, Q, R, $\mathrm{S}, \mathrm{T}, \mathrm{U}, \mathrm{V}, \mathrm{W}$, and $\mathrm{X}$. All were derived from mother plants from the Province of Pontevedra 

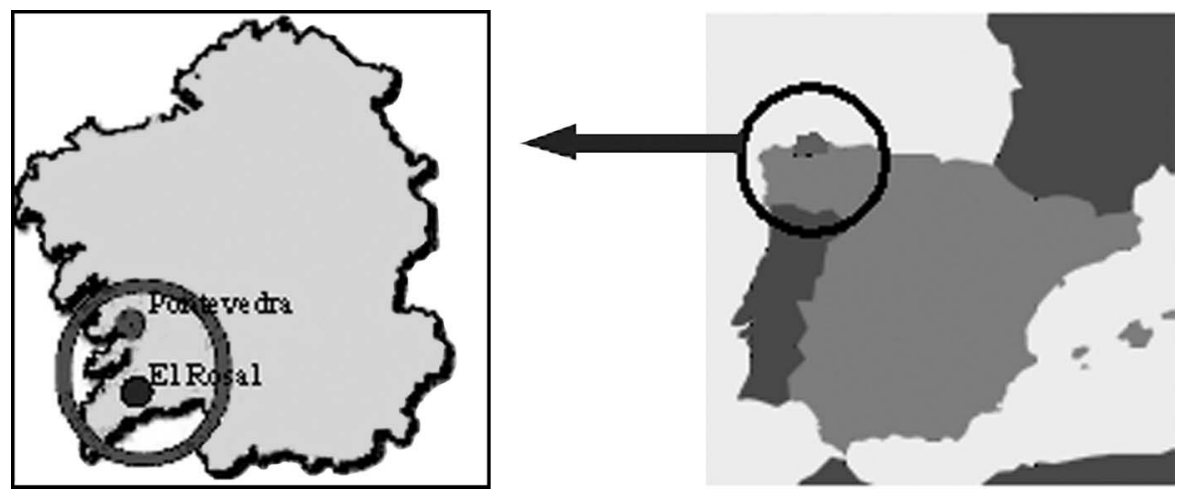

Fig. 1. Location of the study sites.

located between 1989 and 1990. Only 22 were studied because many of the original 115 had begun to show signs of disease and others had died. All of these plants were grafted onto 196-17C stocks and were randomly distributed in the same plot in 1992. A distance of $3.5 \mathrm{~m}$ separated the rows; the plants in each row were separated by $2.5 \mathrm{~m}$. All plants were trained using a trellis-lyre system. The horizontal trunk of the plants was $70 \mathrm{~cm}$ above ground level. Above this, the trellis support posts had three crossbeams at different heights with those of one post connected to those of another by wires (rather like telegraph poles). The wires on the lowest crossbeam help direct the fruiting canes, whereas the higher ones help support the weight of the plant. The pruning system involved leaving renewal spurs with two buds and fruiting canes with seven buds. All plants were subject to the same edaphoclimatic and cultivation conditions. The soil was a sandy loam on a base of schist - quite unusual compared with soils where 'Albariño' plants are normally grown. This schist was accompanied by alkaline quartz incrustations, which may reduce must acidity. The phosphorus content of the soil was $26 \mathrm{ppm}$. The composition of the cation exchange complex was $[\mathrm{cmol}(+) / \mathrm{kg}]: 0.46$ in potassium; 2.69 in magnesium, and 6.61 in calcium. The organic matter content was $5.48 \%$. The mean annual temperature and rainfall values were similar to those of the MBG site. These 22 plants were studied over three seasons (2003-2005).

All MBG and BTG clones were confirmed as belonging to 'Albariño' by ampelographic and molecular analyses (Boso et al., 2005; Loureiro et al., 1998; Martínez et al., 1994).

\section{Sample collection and variables studied}

Fertility and characteristics of clusters, berries, and seeds. The clones were examined for differences at the berry ripening stage. Maturation was monitored during the final month of ripening. When the berries were at optimum ripeness (i.e., when they had stopped concentrating sugar), they were harvested. The number of clusters per shoot of each plant of a clone was counted. They were then removed, placed in a bag, and weighed (yield = kilograms grape/vine).

Ten representative clusters from each clone were then selected according to the norms of the Office International de la Vigne et du Vin (O.I.V., 1983), and their weight, length, width, and number of berries were recorded. The length of the stem was also measured.

Fifty berries per clone were selected and each berry was given a number. The length of the pedicel and the length, width, and weight of the berry were then recorded, and the number of seeds per berry was counted. Once the seeds were dry, 50 from each clone were randomly selected and their individual lengths and weights recorded.

Free-run must yield. Berries from the middle part of each cluster were sampled. The berries were placed in a centrifuge tube, gently ground, and then centrifuged for $3 \mathrm{~min}$ at $3000 \mathrm{rpm}$. The volume of supernatant was measured and the free-run must yield per berry $(\%)$ estimated as follows:

\section{(Free-run must of berries/weight of berries) $\times 100$}

Probable alcohol content. A $50-\mu \mathrm{L}$ sample of the supernatant was taken with a Pasteur pipette and placed in a refractometer to obtain the sugar concentration ( ${ }^{\circ}$ Brix). The probable alcohol content of the juice (degrees Baumé) was estimated using conversion charts.

Total must acidity. Sampling was conducted following the same procedures as for determining the must yield per berry. The total acidity of the must was estimated using the coloration pattern volumetric method (Diario Oficial de Las Comunidades Europeas, 1990).

Must $\mathrm{pH}$. This was recorded with a $\mathrm{pH}$ meter Crison GLP 21 (Crison 08328, Alella, Barcelona, Spain).

Fertility. Taking into account the number of buds left at the last pruning, the fertility index was calculated using the equation:

\section{No. of clusters per plant $X$ \\ $10 /$ no. of buds per plant}

Weight of pruned wood. Pruning was undertaken by the end of February and the wood obtained from each of the 10 specimens per clone was weighed.

Statistical analysis. Principal components analysis (PCA) was performed taking into account all the cluster and must variables and the weight of pruned wood; a second analysis was performed taking into account the berry and seed variables. Analyses were performed separately for the two sites. All calculations were made using SAS System software version 9.1.2 (SAS Institute, 2004).

\section{Results}

\section{MBG clones}

Cluster, must, and pruned wood variables. When PCA was performed with these variables, using the data of 5 years, the first three axes explained $79.35 \%$ of the variance (Prin1: $43.52 \%$, Prin2: $23.77 \%$, and Prin3: $12.06 \%$ ). Figure 2 shows the distribution of the clones with respect to these axes.

With respect to Prin1, the most important variables were the number of berries per cluster (axis weighting 0.35), cluster weight (0.36), cluster length $(0.29)$, cluster width (0.34), total acidity $(-0.30)$, and the yield (kilograms grape/vine) (0.32). A negative correlation was seen between total acidity and the majority of the other variables analyzed. Also with respect to this axis, MBG11, followed by MBG-3 and MBG-9, grouped toward the right of the graph with the heaviest and largest representative clusters, the greatest number of berries per cluster, the greatest total yield (kilograms grape/vine), and the

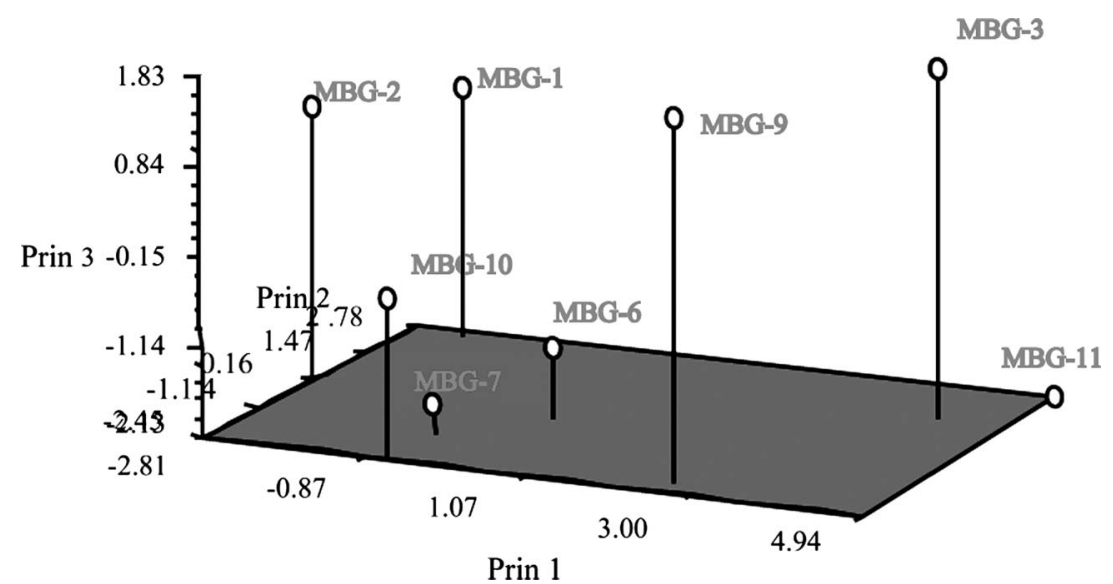

Fig. 2. MBG clones: principal components analysis of cluster and must variables and pruned wood. 
must with the lowest total acidity. Lying at the far left of the graph were MBG-1 and MBG-2 with the opposite characteristics.

With respect to Prin2, the most important variables were the number of clusters per shoot (0.41), the fertility index (0.46), and the weight of pruned wood (0.33). MBG-1 and MBG-11 lay toward the back of the graph with the greatest number of clusters per shoot, the highest fertility indices, and the greatest amount of pruned wood; MBG-9 and MBG-10 lay at the front of the graph with the opposite characteristics.

With respect to Prin3, the most important variable was the probable alcohol content (0.55). MBG-1, MBG-2, MBG-9, and MBG3 lay at the top of the graph with the highest probable alcohol content, whereas MBG-11, with the lowest value, lay at the bottom.

Berry and seed variables. PCA performed with these variables (using the data of 5 years) showed the first three axes to account for $90.02 \%$ of the variance (Prin1: $49.53 \%$, Prin2: $25.43 \%$, and Prin3: $15.05 \%$ ). Figure 3 shows the distribution of the clones with respect to these axes. The most important variables with respect to Prin1 were berry length and width (axis weighting 0.44 and $0.46)$ and pedicel length (0.39). Also with respect to this axis, MBG-6 lay at the right of the graph with the largest berries and the longest pedicels; MBG-11 lay at the left with the smallest berries and shortest pedicels.

With respect to Prin2, the most important variables were seed width $(0.46)$ and berry weight $(-0.41)$. Also with respect to this axis, MBG-7 lay at the far back of the graph with the widest seeds and the lightest berries; MBG-3 and MBG-2 lay toward the front of the graph with the thinnest seeds and the heaviest berries.

With respect to Prin3, the most important variable was the number of seeds per berry (0.83). Also with respect to this axis, MBG-7, MBG-11, MBG-9, MBG-3, and MBG 10 lay at the top of the graph with the most seeds per berry; MBG-2, MBG-6, and MBG-1 lay at the bottom with the smallest number of seeds per berry.

\section{BTG clones}

Cluster, must, and pruned wood variables. The PCA performed with these variables (using the data of 3 years) showed the first three axes to account for $64 \%$ of the variance (Prin1: 34\%, Prin2: 16\%, and Prin3: $13 \%)$. Figure 4 shows the distribution of the clones with respect to these axes.

With respect to Prin1, the most important variables were total acidity (axis weighting 0.37 ), cluster weight (0.34), the total number of clusters per plant $(-0.37)$, and fertility $(-0.37)$. Also with respect to this axis, clone $\mathrm{K}$ lay to the right of the graph, followed by $\mathrm{Q}, \mathrm{B}$, and $\mathrm{D}$, with the most acidic must, the heaviest clusters, the fewest total number of clusters per plant, and the lowest fertility indices. Clones $\mathrm{U}, \mathrm{J}, \mathrm{V}, \mathrm{E}, \mathrm{I}, \mathrm{O}, \mathrm{H}$, and $\mathrm{X}$ lay to the extreme left with the opposite characteristics.

With respect to Prin2, the most important variables were the number of berries per cluster (0.38), the probable alcohol content

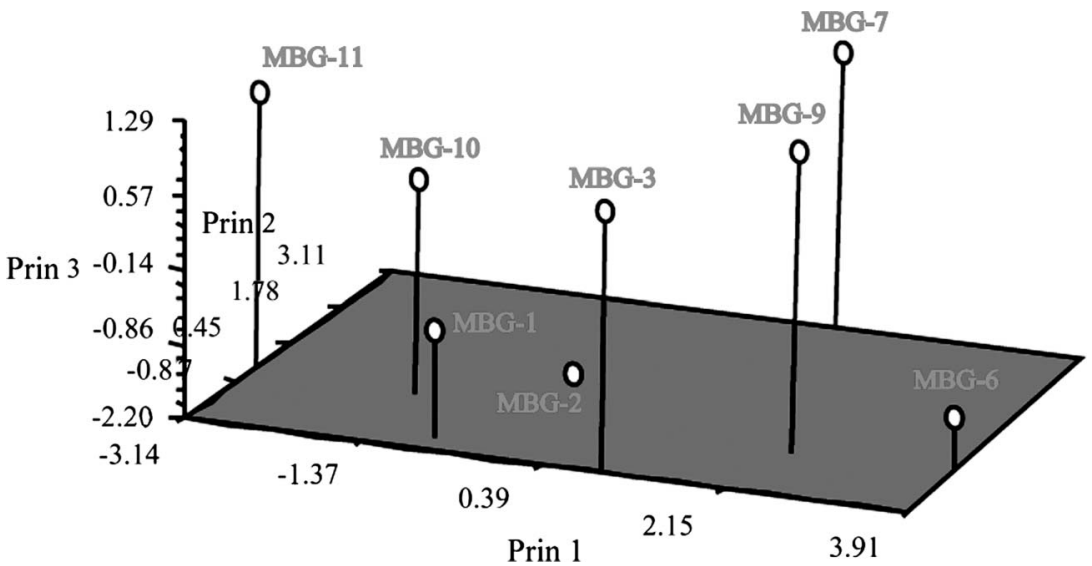

Fig. 3. MBG clones: principal components analysis of seed and berry variables.

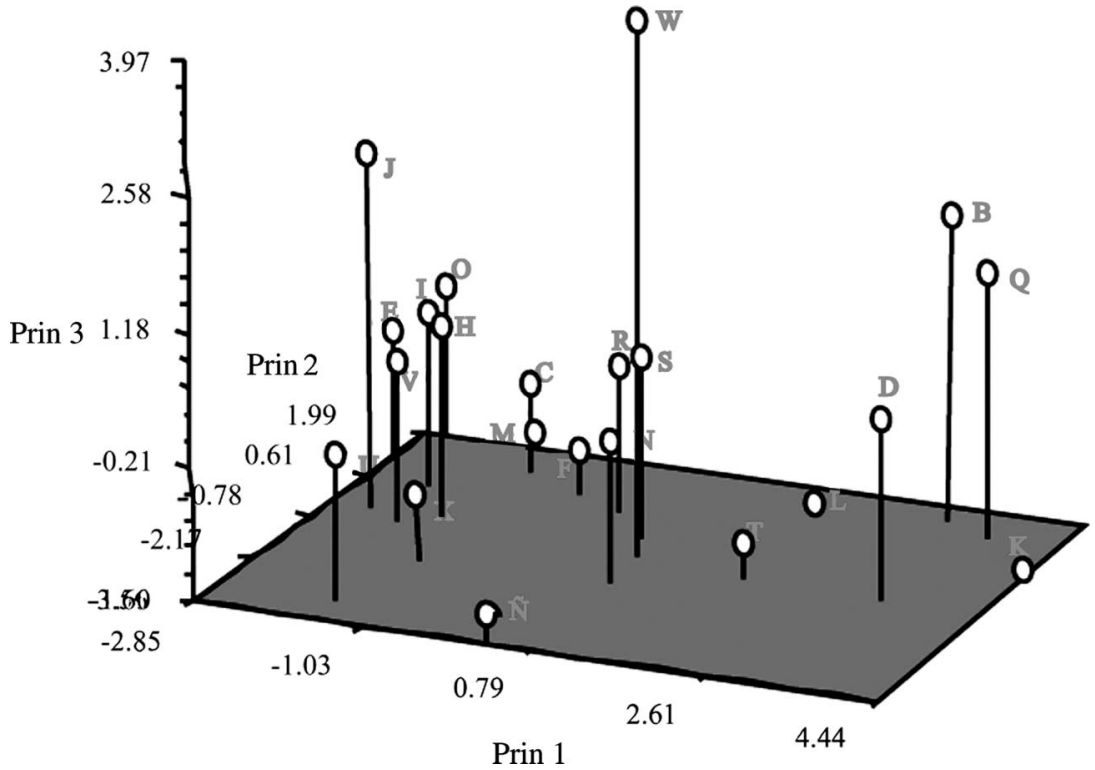

Fig. 4. BTG clones: principal components analysis of cluster and must variables and pruned wood.

(0.32), must $\mathrm{pH}(0.31)$, and the yield (kilograms grape/vine) (0.49). Clones B, Q, O, C, and $\mathrm{M}$ lay at the back of the graph with the greatest number of berries per cluster, the biggest yield (kilograms grape/vine), the must with the greatest probable alcohol content, and the highest must $\mathrm{pH}$.

With respect to Prin3, the most important variables were the length of the cluster peduncle $(0.55)$ and the must yield $(0.43)$. Also with respect to this axis, clone $\mathrm{W}$ lay at the top of the graph with the longest cluster peduncle and the highest must yield; clones $\mathrm{K}, \mathrm{L}, \mathrm{T}, \tilde{\mathrm{N}}, \mathrm{F}$, and $\mathrm{X}$ lay at the bottom of the graph with the opposite characteristics.

Seed and berry variables. In PCA performed with these variables (using the data of three years), the first three axes explained $83 \%$ of the variance (Prin 1: 43\%, Prin2: 25\%, and Prin3: 16\%). Figure 5 shows the distribution of the clones with respect to these axes.

With respect to Prin1, the most important variables were berry length (axis weighting $0.49)$, width (0.50), and weight (0.50). Also with respect to this axis, clone $\mathrm{W}$ lay at the right of the graph (quite separate from the remaining clones) with the largest and heaviest berries; clones $\mathrm{V}$ and $\mathrm{K}$ lay at the left of the graph with the opposite characteristics.

With respect to Prin2, the most important variables were seed length (0.52), width (0.63), and weight $(0.46)$. Also with respect to this axis, clone $\tilde{N}$ appeared at the back of the graph with the largest seeds; clone $\mathrm{H}$ lay at the front of the graph with the smallest seeds. The remaining clones occupied intermediate positions.

With respect to Prin3, the most important variable was the cluster pedicel length (0.80). Also with respect to this axis, clone $\mathrm{Q}$ lay in the upper part of the graph with J, T, R, I, and $\mathrm{D}$ just below with the longest pedicel lengths; clone $\mathrm{V}$ lay at the bottom of the graph with the smallest pedicels.

\section{Discussion}

One of the most intriguing results of this study is that the cluster and must variables and the weight of pruned wood showed less discriminating power at both sites $(79.35 \%$ at 


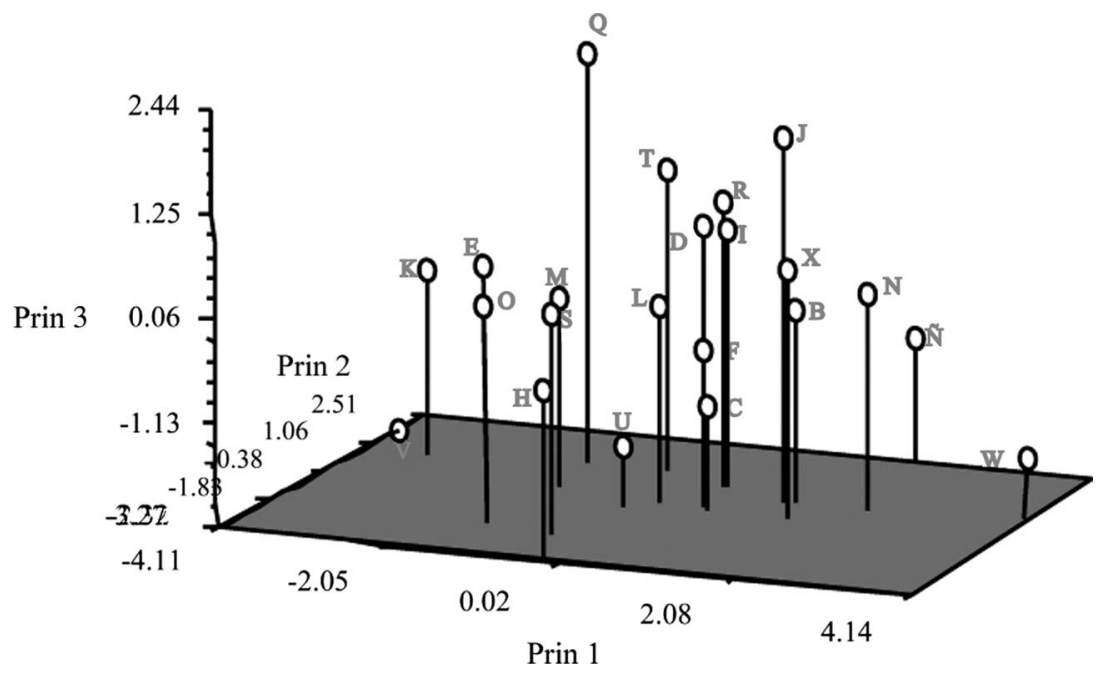

Fig. 5. BTG clones: principal components analysis of seed and berry variables.

the MBG site and $64 \%$ at the BTG site) than the seed and berry variables $(90.02 \%$ at the MBG site and $83 \%$ at the BTG site). The reason for the greater discriminating power of all these variables at the MBG site was probably because 5 years' worth of data were available compared with only 3 years' worth for the BTG site. The higher discriminating power of seed and berry characteristics are the result of their smaller values and the smaller variability within and between clones. The figures recorded may be the result of the influence of climatic conditions on the cluster (cluster size and fertility index) and must (probable alcohol content, and so on) variables as well as plant vigor (represented by the weight of the pruned wood). They also suggest that to obtain reliable data on the characteristics and behavior of different clones (and almost certainly of different varieties), more than 3 years' worth of results are required - the reliability increasing the more years worth of data are available.

PCA involving the cluster and must variables and the weight of pruned wood showed that at both sites, 10 variables were important. However, at the MBG site, the axis weightings of all these variables were greater. In these analyses, the discriminating power of the seed and berry variables was very similar at both sites. This suggests that the climatethe only environmental variable that changed from 1 year to the next - has more influence on the cluster variables, must characteristics, and the amount of pruned wood than on the seed and berry characteristics. Thus, although the size of the clusters or the must characteristics might vary from one year to another, the size of the berries and seeds is likely to be similar.

Six of the cluster/must variables differentiated the clones at both the MBG and BTG sites: cluster weight, number of berries per cluster, fertility index, total acidity, probable alcohol content, and kilograms grapes/vine. The variables related to cluster size, the total number of clusters per plant, and weight of pruned wood were only discriminatory for the MBG clones. The total number of clusters per plant, must
$\mathrm{pH}$, cluster peduncle length, and must yield were only discriminatory for the BTG clones. The reason may again be that only 3 years' worth of data were available for the BTG site; because these variables are strongly influenced by climatic conditions, it might be necessary to collect data over more years to counteract the impact of its affect on the figures.

With respect to the seed and berry variables, berry length, berry width, seed width, and pedicel length were the most discriminating at both sites. The number of seeds per berry was only discriminatory for the MBG clones, whereas seed length and seed weight distinguished clones only at the BTG site. This would seem to confirm that the seed and berry variables are less influenced by climatic conditions; these variables were valid distinguishing features irrespective of whether 3 or 5 years' worth of data were available.

Despite only eight MBG clones being studied, the interclonal variability they showed was greater than that shown by the 22 BTG clones. This shows the importance of making a good preselection (with respect to the ampelographic or agronomic features of the mother plants) of the material to be admitted to a collection (Boidron, 2000; Maigre et al., 1998, 1999) Preliminary preselection work was performed for the MBG collection, and only eight clones were finally admitted. Not only was it first confirmed that all the MBG candidate mother plants were centuries old, but material was taken only from those that showed ampelographic (Martínez et al., 1994) or agronomic differences in situ. The original BTG collection, however, admitted 115 clones without such preselection.

\section{Conclusion}

The results of this work suggest that before collecting specimens and admitting them for use in clonal selection programs, preliminary experiments should be performed on candidate materials to determine whether they truly show ampelographic or agronomic differences. In this way, the num- ber of plants finally admitted to such programs is more manageable and the variation they show is likely to be at least as great as that of larger, less manageable collections.

\section{Literature Cited}

Boidron, R. 2000. Clonal selection in France: Recent evolution and clonal characteristics. French Clonal Seminar, 9 June 2000, Napa, Calif.

Boso, S., M.C. Martínez, S. Unger, and H.-H. Kassemeyer. 2006. Evaluation of foliar resistance to downy mildew in different $\mathrm{cv}$. Albariño clones. Vitis 45:23-27.

Boso, S., J.L. Santiago, and M.C. Martínez. 2004a. Intravarietal agronomic variability in the $\mathrm{cv}$. Albariño (Vitis vinifera L.). Amer. J. Enol. Viticult. 55:279-282.

Boso, S., J.L. Santiago, and M.C. Martínez. 2004b. Resistance of eight different clones of the grape cultivar Albariño to Plasmopara viticola. Plant Dis. 88:741-744.

Boso, S., J.L. Santiago, M. Vilanova, and M.C. Martínez. 2005. Ampelographic and agronomic characteristics in different clones of cultivar Albariño (Vitis vinifera L.). Bulletin de l'OIV 78 (889-890):143-158.

Diario Oficial de las Comunidades Europeas. (D.O.C.E.). 1990. Métodos oficiales de análisis. Acidez total. Método volumétrico con patrón de coloración.

Loureiro, M.D., M.C. Martínez, J.M. Boursiquot, and P. This. 1998. Molecular marker analysis of Vitis vinifera Albariño in some similar grapevine cultivars. J. Amer. Soc. Hort. Sci. 123:842-848.

Maigre, D., J. Aerny, and F. Murisier. 1998. Comparación de clones de Pinot noir. I. Résults agronomiques. Revue Suisse Viticult. Arbor. Hort. 30:361-368.

Maigre, D., J. Aerny, and F. Murisier. 1999. Comparación de clones de Pinot noir. II. Résults analytiques et organoleptiques. Revue Suisse Viticult. Arbor. Hort. 31:183-189.

Martínez, M.C., S. Boso, and J.L. Santiago. 2005. Los clones de Albariño (Vitis vinifera L.) seleccionados en el Consejo Superior de Investigaciones Científicas. Departamento de Publicaciones del CSIC, Biblioteca de Ciencias: No. 19 Madrid, Spain.

Martínez, M.C. and J.L.G. Mantilla. 1993. Descripción y comparación ampelográfica de cepas de Vitis vinifera L., cv. Albariño adultas (procedentes de estaquillado de cepas viejas), de propagación in vitro y de semilla, cuando tienen un año. Vitis 32:245-246.

Martínez, M.C. and J.L.G. Mantilla. 1994. Estudio ampelográfico de cepas de Vitis vinifera L., cv. Albariño procedentes de micropropagación in vitro, en comparación con plantas de semilla y adultas de dos años y no sometidas a poda. Investigación Agraria. Producción y Protección Vegetales 9:201-211.

Martínez, M.C., J.L.G. Mantilla, and M.D. Loureiro. 1994. Descripción ampelográfica sobre hoja adulta de cepas de Vitis vinifera L. denominadas Albariño. Viticultura y Enología Profesional 34:30-40.

Ministerio de Agricultura Pesca y Alimentación. 1988. Reglamento de la Denominación de Origen Rías Baixas y su Consejo Regulador, Orden Ministerial del 02/VIII/88. Boletín Oficial del Estado, p. 10126-10130.

Office International de la Vigne et du Vin. (O.I.V.). 1983. Le code des caractères descriptifs des variétés et espéces de Vitis. Dedon, Paris.

SAS System software, version 9.1.2. 2004. SAS Institute, Cary, N.C. 